\title{
Ascent Trajectories of Hypersonic Aircraft: Operability Limits Due to Engine Unstart
}

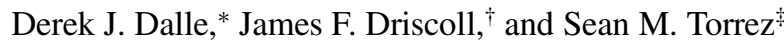 \\ University of Michigan, Ann Arbor, Michigan 48109
}

DOI: $\underline{10.2514 / 1 . C 032801}$

\begin{abstract}
A generic waverider-type hypersonic aircraft that undergoes an ascent trajectory has been modeled using a firstprinciples reduced-order model. Two types of operability limits are added that represent boundaries on the aircraft trajectory map (of vehicle altitude versus Mach number). These boundaries are associated with engine unstart and ram-scram transition. The predicted unstart boundary is to be avoided; the ram-scram transition is a condition through which the aircraft must fly, but it is useful for the control system to know when this transition is approached to account for possible sudden changes in thrust and moments. The model shows that unstart occurs if the aircraft flies too high, too slow, or at too great of an acceleration. The unstart limit can be avoided by selecting a trajectory having sufficiently large dynamic pressure or a low vehicle acceleration. Optimizing these factors avoids an excessive value of the fuel-air ratio that is required for trim. The model also identifies an engine inlet geometry that avoids unstart. To assess the model, the computed results are compared to some available experiments.
\end{abstract}

\section{Nomenclature}

$A \quad=$ area

$C_{D} \quad=$ drag coefficient

$C_{T} \quad=$ thrust coefficient

$c_{f} \quad=$ friction coefficient

$\begin{array}{ll}c_{p} & =\text { specific heat at constant pressure } \\ D & =\text { hydraulic diameter }\end{array}$

ER

$H$

$h$

$L$

$M$

$M_{\text {design }}$

$m$

$\dot{m}$

$p$

$Q_{R}$

$q_{\infty}$

$r_{A}$

$r_{p}$

$r_{\mathrm{st}}$

$S$

$T$

$U_{\infty}$

$u$.

$\dot{V}$

$W$

$x$

$Y$

$\alpha$

$\beta$

$\gamma$

$\Delta T_{0}$

hydraulic diameter

equivalence ratio

height of isolator

altitude

length

Mach number

design Mach number

vehicle mass

mass flow rate

pressure

fuel heating value

flight dynamic pressure

inlet compression ratio

stoichiometric fual-air mass ratio

reference area

temperature

flight speed

local flow speed

acceleration along velocity vector

axial coordinate

species mass fraction

- vehicle angle of attack

unstart margin

ratio of specific heats

= change in stagnation temperature core flow area over geometric area

molecular weight or vehicle weight

Received 8 April 2014; revision received 3 July 2014; accepted for publication 13 August 2014; published online 25 November 2014. Copyright (C) 2014 by Derek J. Dalle. Published by the American Institute of Aeronautics and Astronautics, Inc., with permission. Copies of this paper may be made for personal or internal use, on condition that the copier pay the $\$ 10.00$ per-copy fee to the Copyright Clearance Center, Inc., 222 Rosewood Drive, Danvers, MA 01923; include the code 1533-3868/14 and $\$ 10.00$ in correspondence with the CCC.

*Postdoctoral Research Fellow, Department of Aerospace Engineering; dalle@umich.edu. Member AIAA.

'Professor, Department of Aerospace Engineering; jamesfd@umich.edu. Fellow AIAA.

${ }^{\ddagger}$ Graduate Research Assistant, Department of Aerospace Engineering; smtorrez@umich.edu. Member AIAA.

$\begin{array}{ll}\theta_{c} & =\text { combustor divergence angle } \\ \theta_{F} & =\text { fuel injection angle } \\ \rho & =\text { density } \\ \dot{\omega} & =\text { chemical reaction rate }\end{array}$

Subscripts

$\begin{array}{lll}A & = & \text { core (primary) flow in duct } \\ C & = & \text { along jet centerline } \\ F & = & \text { fuel injector } \\ \text { ISO } & = & \text { isolator } \\ \text { RS } & = & \text { ram-scram transition } \\ \text { ST } & = & \text { shock train } \\ w & = & \text { wall } \\ 0 & = & \text { stagnation value } \\ 2 & = & \text { boundary between inlet and isolator } \\ 3 & = & \text { end of isolator } \\ 4 & = & \text { combustor choke point } \\ \infty & = & \text { freestream or flight condition }\end{array}$

\section{Introduction}

$\mathbf{T}$ HE Bolender-Doman U.S. Air Force Research Laboratory (AFRL) model of hypersonic aircraft [1] was reported in 2007, and it has been used in several studies to predict flight dynamics, control strategies, and the effects of vehicle bending [2-4]. For example, Parker et al. [2] used the AFRL model of a generic vehicle to investigate a flexible hypersonic vehicle. Skujins et al. [3] and Oppenheimer et al. [4] demonstrated that, as the aircraft bends, the locations of the shock waves move, and this affects the effectiveness of control surfaces and changes the spillage of the air that bypasses the engine, which affects the thrust. The Bolender-Doman AFRL model is a first-principles reduced-order model, which means that the fundamental conservation equations are solved, but certain twodimensional (2-D) and one-dimensional (1-D) assumptions are made to reduce the complexity of the problem. Their engine flow was assumed to be 1-D, the bow shock was assumed to be 2-D, and they ignored interactions between any shock waves. Reduced-order models also have been used for aircraft design by $\mathrm{O}^{\prime} \mathrm{Neill}$ and Lewis [5] and Bowcutt [6]. McQuade et al. [7] developed a different type of reduced-order model that reduces the number of computational fluid dynamics (CFD) runs required to optimize the design of a hypersonic aircraft. Mor and Livne [8] optimized the trajectory of a reentry vehicle and developed a new way to simultaneously optimize the vehicle shape and size.

The present authors improve upon the Bolender-Doman AFRL model to avoid some of the assumptions that were made in the original model [요며․ Recently, we have developed a methodology 
that has enabled the computation of both the engine unstart and the ram-scram transition boundaries for a trimmed waverider vehicle [11]. The improved model is called the MASTrim (from "Michigan/ AFRL scramjet trim") code. The new methodology is only briefly reviewed in Sec. III because details have appeared in [9-12]. The present effort goes beyond the methodology in [11], and it applies the model to achieve the following goals. A generic waverider is trimmed at each point along an ascent trajectory assuming constant dynamic pressure, and the boundaries at which unstart and ram-scram transition occur are computed. Previously, there have been a few related efforts in this general direction. Chichka et al. [13] and Rodriguez et al. [14] plotted thermal choking boundaries along an ascent trajectory. Starkey and Lewis [15] and others [16-22] also reported control-oriented models of hypersonic vehicles. However, in all of the previous studies, the unstart limits and the ram-scram transition boundaries were not computed.

The model described in Sec. III is a reduced-order model. Shockexpansion theory is employed to compute aerodynamic forces on the aircraft, and this theory is limited to slender bodies at small angles of attack. Only a 2-D engine geometry is considered, but this is reasonable because some realistic vehicles contain long, thin rectangular engine inlets. The 2-D inlet shock and expansion wave interactions are modeled using an approach similar to the method of characteristics. Viscous forces are included, but only in an empirical manner. Engine fual-air mixing and finite-rate combustion chemistry are not assumed to be 1-D; instead three-dimensional (3-D) similarity solutions are used to compute the reaction rates of a fuel jet in a crossflow using a flamelet model.

Reduced-order models (ROMs) are commonly used to design a control algorithm or to obtain a first estimate of an optimal aircraft design. The MASTrim code computes aerodynamic forces and engine thrust by solving ordinary differential equations in less than $5 \mathrm{~s}$ on a single $2.6 \mathrm{GHz}$ processor (when the engine is in the scramjet mode). In the ramjet mode, the computational time currently is $30 \mathrm{~s}$ because the conditions for thermal choking are found iteratively. Suppose that it is desired to compute the aircraft forces, moments, and the trimmed angle of attack at each point along six possible trajectories. Forces must be computed approximately 1800 times. This is because, for each of the six trajectories, the vehicle must be trimmed at approximately 20 different altitudes; at each altitude, forces have to be computed about 15 times to determine by iteration what angle of attack, equivalence ratio, and elevator setting trim the vehicle. High-fidelity CFD computations are more accurate than reduced-order models, but they are not appropriate in early design and analysis cycles for determining performance at thousands of combinations of flight condition and control inputs needed for analysis of ascent trajectories, design optimization, and control applications. The disadvantages of reduced-order models are that their levels of accuracy must be determined by validation studies and that they are only valid for specific geometries (for which the lookup tables were generated). In this case, only quasi-steady changes are considered. The advantage of a first-principles ROM such as MASTrim is that the fundamental conservation equations are solved. Although 2-D or 1-D assumptions are employed, still it is possible to interrogate the physics to better understand any model predictions that appear to be interesting. A ROM also provides a "first look" at a large parameter space. The ROM can identify certain optimal conditions for which relatively few high-fidelity CFD runs then can be performed.

\section{Research Goals}

The first goal is to apply the MASTrim code to trim the generic waverider that is shown in Fig. 1 as it ascends along the constant dynamic pressure trajectory that is sketched in Fig. 2. The next goal is to compute the two points A and B that identify the occurrence of engine unstart and ram-scram transition, respectively. The ramjet engine cannot be ignited to the left of point $\mathrm{A}$ or it would unstart, and so it typically would be ignited at point $\mathrm{B}$. The vehicle ascends in the ram mode to point $C$ when ram-scram transition occurs. At point $D$, the engine begins its scram-mode operation. The challenge is that the

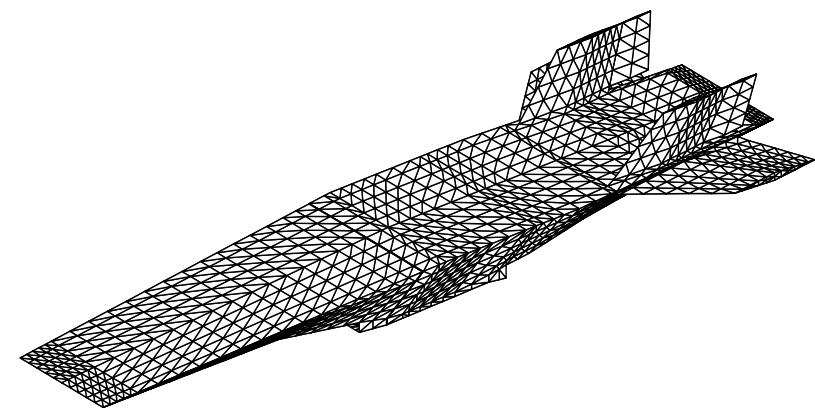

a) MAX-1 hypersonic vehicle

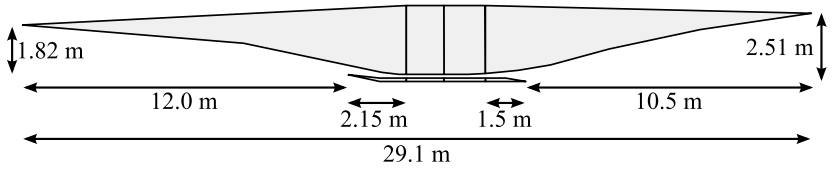

b) Inlet and nozzle dimensions

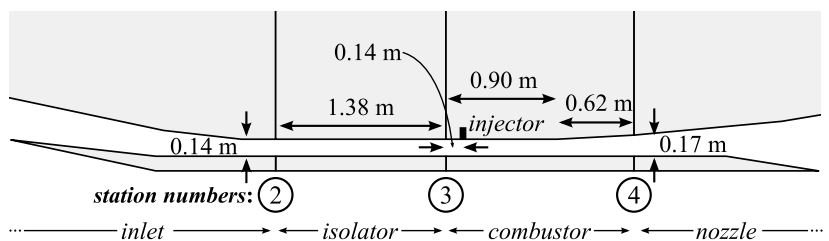

c) Internal flowpath dimensions

Fig. 1 MAX-1 vehicle and flowpath dimensions. Engine width is $2.143 \mathrm{~m}$.

pilot or flight control system does not directly control whether the engine is in the ram or the scram mode; instead, the mode is primarily determined by the fual-air equivalence ratio (ER), which must be set to the value that gives the desired acceleration for the trimmed aircraft. Thus, ER depends on the vehicle speed, altitude (or dynamic pressure, alternatively), and the desired acceleration. The next goal is to compute points that are similar to $\mathrm{A}$ and $\mathrm{C}$ for many dynamic pressures. These points then are connected to create an unstart boundary as well as a ram-scram transition boundary. This allows one to select complex trajectories that, for example, minimize fuel consumption or the time to ascend and yet avoid crossing the unstart boundary. Knowing the location of the ram-scram boundary allows the trajectory to be selected so that ram-scram transition occurs at a desired flight Mach number, which may be advantageous for the control system.

The MAX-1 vehicle geometry is similar to the generic aircraft that was first considered by Bolender and Doman [1]. Its length is $29.1 \mathrm{~m}$ $(95.4 \mathrm{ft})$, and the inlet to the dual-mode ramjet-scramjet engine is rectangular with a sufficiently large aspect ratio of 15.3 such that it can be considered two-dimensional. The approach of the AFRL program has been to maintain the same geometry but to make gradual improvements to make it more realistic. Previously, the sizes of the control surfaces were optimized [2], the weight distribution was altered [4], and aeroelastic properties were added [2,4].

The present effort adds the engine unstart boundaries. Several different definitions exist in the literature. Ram mode is defined to occur when the local Mach number at the fuel injector is less than 1; scram mode occurs when this Mach number exceeds 1 . In the ram mode, thermal choking occurs because there is no geometric throat in the dual-mode geometry in Fig. 1. Backpressure from the thermal choking causes a precombustion shock train to form in the isolator, which reduces the Mach number to a subsonic value at the fuel injector.

One cause of engine unstart is setting the fuel equivalence ratio to an excessive value. The model shows that this causes an increase in the backpressure on the isolator that is drawn in Fig. 1. The high backpressure increases the length of the shock train until the shock train exceeds the length of the isolator. Unstart begins when shock 
waves first move upstream into the inlet and cause spillage of some air that no longer enters the engine, and so thrust is reduced. A second type of unstart also is considered; it occurs when the static pressure rise across the isolator shock train exceeds that of a normal shock.

The unstart limit is defined here to be the incipient, quasi-steady limit. Incipient means that our analysis is limited to predicting the condition just before the isolator shocks begin to interact with the inlet shocks. This is the point when thrust performance begins to decrease. This limit that we compute is an important boundary, but there are later shock interactions that are unsteady in nature. It is beyond the scope of this paper to compute the later events. Unstart limits in this work also are limited to small vehicle angles of attack and sideslip. The analysis does not consider nonuniform air flow caused by large sideslip angles. Understanding the quasi-steady incipient unstart limit for small angles of attack and sideslip is an important first step that is necessary before more complex phenomena can be analyzed. Section III describes the vehicle and engine models, with the method to determine ram-scram transition in Sec. III.G and the method to determine the unstart limit in Sec. III.F. Finally, results for the combined vehicle mode are presented in Sec. IV.

\section{MASIV Engine Model}

This section is a description of the MASIV submodels of the engine inlet, combustor, and nozzle. Also included are the methods used to compute thermal choking, ram-scram transition, and unstart.

\section{A. Inlet and Nozzle Modeling}

The inlet and nozzle use a model called supersonic aerodynamic method using riemann interactions (SAMURI). Its use for modeling inlets was described in [9], and its use in hypersonic nozzles was described in [12]. It is assumed that the inlet and nozzles have a 2-D geometry, and 3-D nonuniformities are small. The flow is steady, and real-gas properties are included. Each panel on the inlet wall generates a wave. The 2-D shock and expansion wave equations are applied, except that continuous expansion fans are discretized into a finite number (typically four) of discrete waves. Where waves intersect, a slip line is formed, and a Riemann problem is imposed.

Figure 3 gives an example solution for trimmed Mach 8 flight, which can be calculated in less than $1 \mathrm{~s}$ on a single $2.6 \mathrm{GHz}$ processor. The bow shock in Fig. $3 \mathrm{~b}$ lies below the cowl lip, and so some flow spillage occurs. Complex wave interactions raise the static temperature to above $750 \mathrm{~K}$ in some locations. On the right-hand side of Fig. $3 \mathrm{~b}$, the flow is seen to be nonuniform due to many wave crossings; flow properties are spatially averaged in the vertical direction to provide single values of pressure, temperature, and velocity as input to the 1-D isolator model. The averaging method ensures that mass, momentum, and energy are conserved [9].

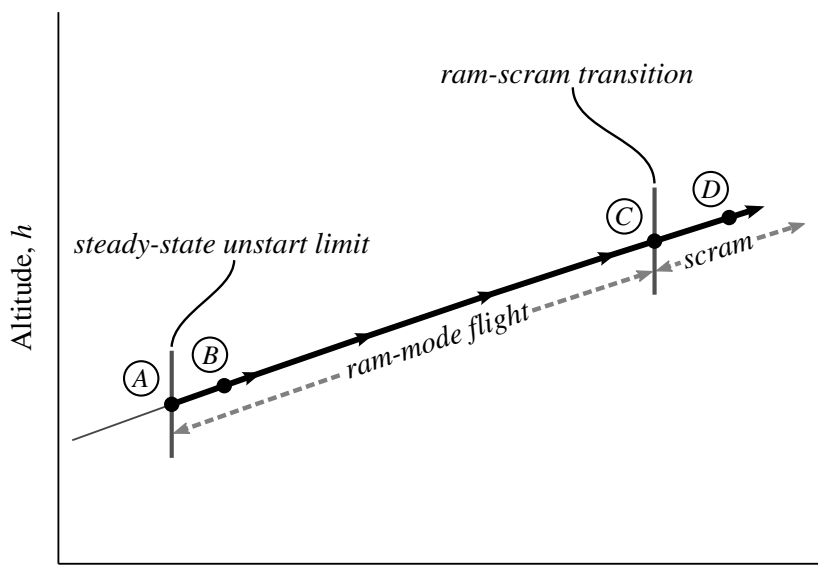

Flight Mach number, $M$

Fig. 2 Schematic of a constant-dynamic-pressure trajectory on the flight corridor map; the unstart limit is point $A$, and the ram-scram transition point is point $C$.

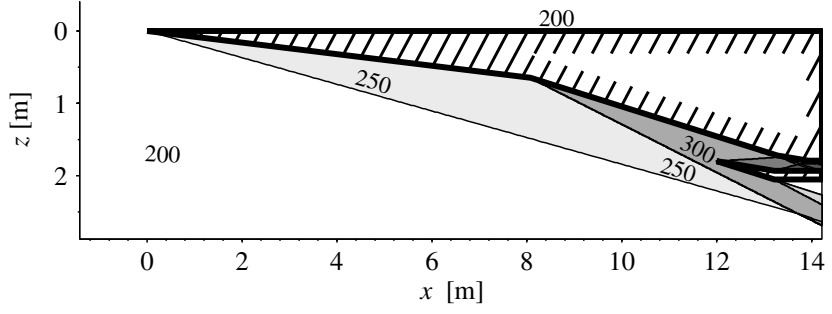

a) Inlet

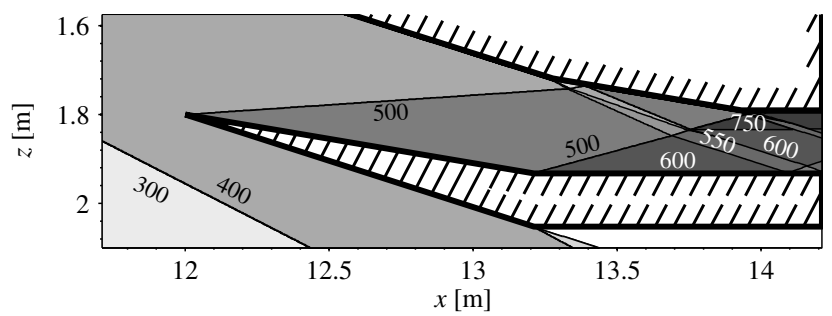

b) Inlet cowl region

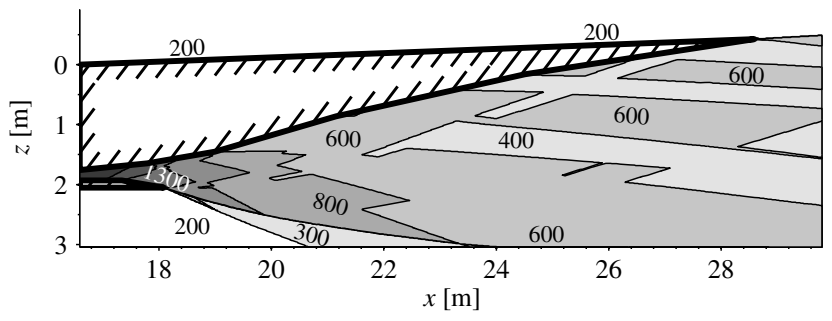

c) Nozzle

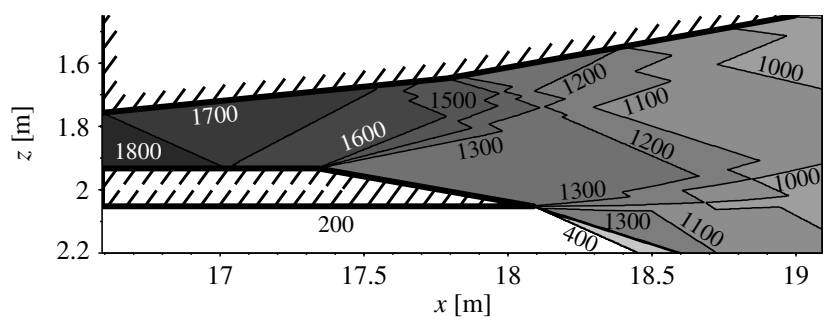

d) Nozzle cowl region

Fig. 3 Contours of temperature in kelvins at a trimmed Mach 8 flight condition calculated using SAMURI.

\section{B. Combustor Model}

The MASIV combustor code was described in detail in $[10,11]$. This code includes finite-rate chemistry, real-gas properties, a threedimensional jet mixing model, a separated boundary-layer model, and gas dissociation. The airstream is modeled as a 1-D flow in a duct with variable area, friction, and wall heat transfer. A 3-D pattern of fuel jets in a crossflow is superimposed on this 1-D flow. The jets issue from the sidewall at different spanwise locations, but all are located at the same axial coordinate. MASIV solves the following seven ordinary differential equations, which include the conservation of mass, momentum, energy, and species:

$$
\begin{gathered}
\frac{1}{\rho} \frac{\mathrm{d} \rho}{\mathrm{d} x}=\frac{1}{\dot{m}} \frac{\mathrm{d} \dot{m}}{\mathrm{~d} x}-\frac{1}{u} \frac{\mathrm{d} u}{\mathrm{~d} x}-\frac{1}{A} \frac{\mathrm{d} A}{\mathrm{~d} x} \\
\frac{1}{u} \frac{\mathrm{d} u}{\mathrm{~d} x}=-\frac{1}{\rho u^{2}} \frac{\mathrm{d} p}{\mathrm{~d} x}-\frac{2 c_{f}}{D}+\left(1-\frac{u_{F}}{u}\right) \frac{1}{\dot{m}} \frac{\mathrm{d} \dot{m}}{\mathrm{~d} x}
\end{gathered}
$$

$$
\frac{1}{p} \frac{\mathrm{d} p}{\mathrm{~d} x}=\frac{1 \mathrm{~d} p}{\rho} \frac{1 \mathrm{~d} T}{\mathrm{~d} x}+\frac{\mathrm{d} T}{T} \frac{1}{\mathrm{~d} x} \frac{\mathrm{d} W}{W}
$$




$$
\frac{1}{W} \frac{\mathrm{d} W}{\mathrm{~d} x}=-\sum_{i=1}^{n_{\mathrm{sp}}} \frac{W}{W_{i}} \frac{\mathrm{d} Y_{i}}{\mathrm{~d} x}
$$

$$
\frac{\mathrm{d} \dot{m}}{\mathrm{~d} x}=\sum_{i=1}^{n_{\mathrm{sp}}} \frac{\mathrm{d} \dot{m}_{i, F}}{\mathrm{~d} x}
$$

$$
c_{p} \frac{\mathrm{d} T}{\mathrm{~d} x}=\frac{h_{0, F}-h_{0}}{\dot{m}} \frac{\mathrm{d} \dot{m}}{\mathrm{~d} x}-\frac{2 c_{f} c_{p}\left(T_{a w}-T_{w}\right)}{\operatorname{Pr}^{2 / 3} D}-u \frac{\mathrm{d} u}{\mathrm{~d} x}-\sum_{i=1}^{n_{\mathrm{sp}}} h_{i} \frac{\mathrm{d} Y_{i}}{\mathrm{~d} x}
$$

$$
\frac{\mathrm{d} Y_{i}}{\mathrm{~d} x}=\frac{\dot{\omega}_{i} W_{i} A}{\dot{m}}+\frac{1}{\dot{m}} \frac{\mathrm{d} \dot{m}_{i, F}}{\mathrm{~d} x}-\frac{Y_{i}}{\dot{m}} \frac{\mathrm{d} \dot{m}}{\mathrm{~d} x}
$$

The quantities in the previous equations are defined in the nomenclature section, and a more complete description is given in [10]. For the hydrogen fuel considered in this work, there are eight species, each with a different mass fraction $Y_{i}$ whose conservation is governed by Eq. (7).

To solve the conservation equations, it is required that the profile of the chemical reaction rate $\dot{\omega}_{i}(x)$ of each species be supplied to the first term on the right-hand side of Eq. (7). Fual-air mixing and combustion cannot be properly simulated by a 1-D model, and so a 3-D mixing/combustion reduced-order model was developed, and it is described in [10]. The fuel is injected as a jet in a crossflow, and the jet centerline coordinate $y_{C}$ has been measured [23-25] to be

$$
\frac{y_{C}}{d_{F}}=c_{2}\left(\frac{x_{C}}{d_{F}}\right)^{1 / 3} R^{2 / 3}
$$

where $x_{C}$ is the axial distance from the injector, $d_{F}$ is the fuel jet diameter, and $R$ is the fuel jet momentum ratio:

$$
R=\sqrt{\frac{\rho_{F}}{\rho_{A}} \frac{u_{F}^{2}}{u_{A}^{2}}}
$$

Along this curved jet centerline, the mean fuel mass fraction has been measured to be

$$
Y_{F, C}=c_{3}\left(\frac{\rho_{F}}{\rho_{A}}\right)^{1 / 3}\left(\frac{u_{F}}{u_{A}}\right)^{-1 / 3}\left(\frac{x_{C}}{d_{F}}\right)^{-2 / 3}
$$

The mean fuel mass fraction also follows a Gaussian profile in the direction that is normal to the curved jet centerline. The standard deviation of fuel mass fraction fluctuations $\left(Y_{F, C}^{\prime \prime}\right)$ also follows a measured scaling law $[\underline{23}, 24]$. Although the scaling laws used for this work were measured in subsonic flow, previously published work has shown that the heat release predicted by these relations is in agreement with experimental results for supersonic combustion (see Fig. 6 in [11]).

These equations define a three-dimensional field for the mixture fraction and the fluctuation of mixture fraction along with a onedimensional pressure and temperature field from Eqs. (1-7). Using a flamelet model, the production rate of each species $i$ is

$$
\dot{\omega}_{i}(x, y, z)=f\left(Y, Y^{\prime \prime}, p, T\right)
$$

which is calculated for species $i=1, \ldots, n$ and at each point in the three-dimensional combustor domain. The production rates in Eq. (7) are determined by integrating the local reaction rates across the two nonaxial coordinates:

$$
\dot{\omega}_{i}(x)=\iint_{A} \dot{\omega}_{i}(x, y, z) \mathrm{d} y \mathrm{~d} z
$$

See Figs. 1, 2 of [10] for a visualization of this mixing model.

The flamelet tables are similar to those generated by Fluent [26]. The advantage of the reduced-order method is that, once the large lookup tables for chemical reaction rates and turbulent mixing properties are generated, they can be rapidly accessed by MASIV. Using this three-dimensional jet-in-crossflow approach gives a level of insight into the mixing that would not be possible with an empirical one-dimensional relationship. In particular, it can be used to make predictions for very high Mach numbers and arrays of injectors for which experimental data are not yet available. The disadvantages are that the generation of the lookup tables takes considerable time, and if the fuel is not hydrogen or the fuel is not injected as a jet in crossflow, additional lookup tables must be generated.

\section{MASIV Isolator Model}

The isolator model of Heiser and Pratt [27] is used to relate the pressure rise, separated boundary-layer size, and exit Mach number. They derived the following relation using the equations for conservation of mass and momentum across the isolator, assuming that the shock train separates the flow into two separate streams (the central core flow and the low-speed separated boundary layer):

$$
\frac{p_{3}}{p_{2}}=1+\gamma M_{2}^{2}-\gamma M_{2} M_{3} \sqrt{\frac{1+(\gamma-1 / 2) M_{2}^{2}}{1+(\gamma-1 / 2) M_{3}^{2}}}
$$

The values of $p_{2}$ and $M_{2}$ (at the isolator entrance; see Fig. 1) are determined by the inlet model, and the MASIV algorithm guesses a value of $M_{3}$ until the correct value is found to satisfy thermal choking constraints as described in Sec. III.E. The isolator contains complex shock patterns and boundary-layer separation, but these processes are not modeled in this work because Eq. (13) relates the upstream conditions $\left(p_{2}, M_{2}\right)$ to the downstream conditions $\left(p_{3}, M_{3}\right)$. This does not account for unsteady or nonuniform effects that could also contribute to unstart phenomena.

Once $p_{3}$ has been computed from Eq. (13), Heiser and Pratt [27] also derived the following expression for the core area of the flow at the combustor inlet:

$$
r_{3 A}=\frac{A_{3 c}}{A_{2}}=\frac{1}{\gamma M_{3}^{2}}\left(\left(1+\gamma M_{2}^{2}\right) \frac{p_{2}}{p_{3}}-1\right)
$$

A brief summary of the conservation equations leading to Eqs. (13) and (14) appears in Appendix A. The remainder of the geometric area at the combustor inlet, $A_{3}-\overline{A_{3 c}}$, is a separated boundary layer with pressure but no momentum.

\section{Separated Flow During Ram-Mode Operation}

A correction is included in the combustor model during ram-mode operation to account for the separated boundary layer that results from the precombustion shock train in the isolator. In the scram mode, the shock train is weak. However, in ram mode, the shock train causes the isolator boundary layer to separate, and so the flow entering the combustor has a core area that is less than the geometric area. The flow reattaches at some point in the combustor because of the favorable pressure gradient that occurs during subsonic combustion. For the ram mode, the core area $A_{c}$ replaces the geometric area $A$ in Eq. (1), and we define $r_{A}$ to be the ratio of core area to geometric area:

$$
r_{A}=A_{c} / A
$$

The ratio of core area to geometric area at the upstream of the combustor, $r_{3 A}=A_{3 c} / A$, is determined by the isolator model of Hesier and Pratt [27] that is described in Sec. III.C, and an additional equation is required to determine how $r_{A}$ changes in the combustor. In this work, it is assumed that $r_{A}$ varies so that the heat addition in the combustor occurs at a constant pressure, which was also suggested by 


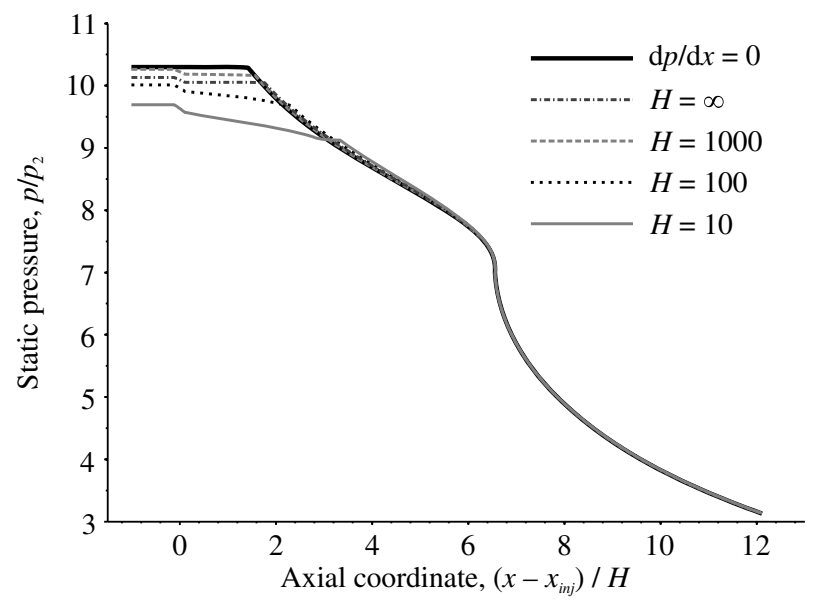

Fig. 4 Static pressure profiles for separated boundary-layer models. One is the constant-pressure assumption and the others use von Kármán integral equations with a constant shape factor $H$.

Heiser and Pratt for supersonic combustion with a separated boundary layer. Another possible assumption is to use the von Kármán integral boundary-layer equations with a fixed shape factor. Figure 4 shows that both approaches yield essentially the same results. Measurements of Fotia and Driscoll [28] verify that the assumption of constant-pressure combustion is valid for their experiment, as shown in Fig. 5, and so this approach was used. This assumption may not be true in other geometries; it is only valid for the geometry used in this work based on experimental validation.

When a separated boundary layer is present, Eqs. (1 $)$ and (2) become

$$
\frac{1}{\rho} \frac{\mathrm{d} \rho}{\mathrm{d} x}=\frac{1}{\dot{m}} \frac{\mathrm{d} \dot{m}}{\mathrm{~d} x}-\frac{1}{u} \frac{\mathrm{d} u}{\mathrm{~d} x}-\frac{1}{A} \frac{\mathrm{d} A}{\mathrm{~d} x}-\frac{1}{r_{A}} \frac{\mathrm{d} r_{A}}{\mathrm{~d} x}
$$

$$
\frac{1}{u} \frac{\mathrm{d} u}{\mathrm{~d} x}=-\frac{1}{\rho u^{2} r_{A}} \frac{\mathrm{d} p}{\mathrm{~d} x}-\frac{2 c_{f}}{D}+\left(1-\frac{u_{F}}{u}\right) \frac{1}{\dot{m}} \frac{\mathrm{d} \dot{m}}{\mathrm{~d} x}
$$

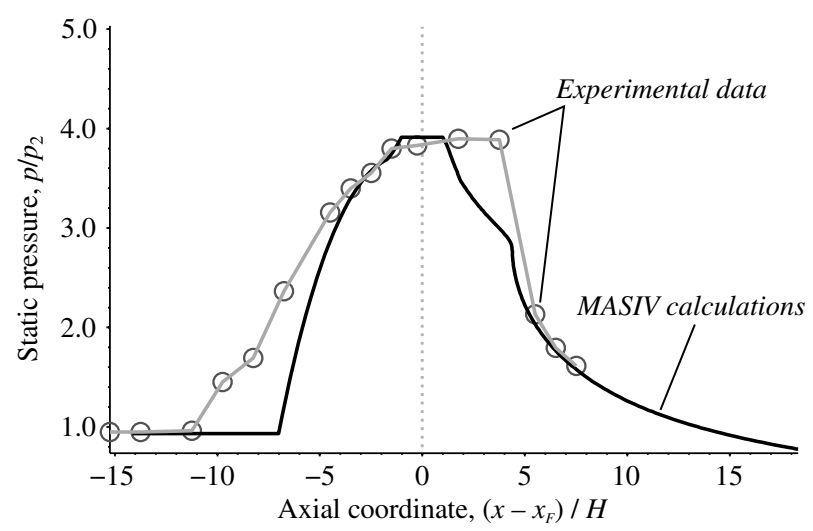

a) Static pressure for $\mathrm{ER}=\mathbf{0 . 3 0 1}$ test case

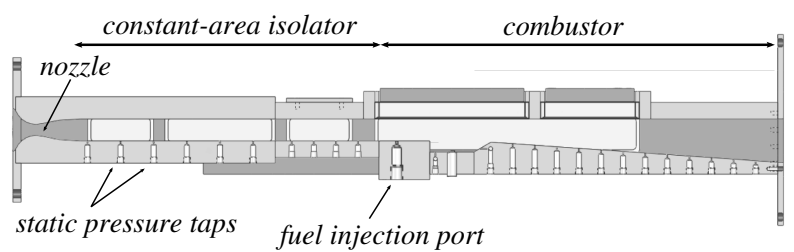

b) Lab-scale geometry

Fig. 5 Comparison of pressure predictions from MASIV and experimental data from [28]. and an additional equation is needed to determine the value of $\mathrm{d} r_{A} / \mathrm{d} x$.

It was shown in [11] that MASIV predicts pressure profiles that match those of the experiment of Fotia and Driscoll [28] if the constants in the Eqs. (8) and (10) are properly chosen. The resulting values chosen for the constants fall within the range of values that were reported in previous experiments $[24,25]$.

\section{E. Thermal Choking}

In ram-mode operation, there is a downstream boundary condition in the engine flowpath involving the point where the flow passes through Mach 1. This point is the thermal choking location $x_{C}$. Shapiro [29] describes the general method to determine $x_{C}$. He explains that a singularity occurs because of a $\left(1-M^{2}\right)^{-1}$ in the denominator of the conservation equations, and an application of l'Hospital's rule yields a condition for $x_{C}$ that must be met to ensure that the flow can be solved through the singularity. The resulting condition is that

$$
\frac{1}{A} \frac{\mathrm{d} A}{\mathrm{~d} x}=\frac{\gamma+1}{2} \frac{1}{T_{0}} \frac{\mathrm{d} T_{0}}{\mathrm{~d} x}
$$

Shapiro explains that $M_{3}$ is determined by solving the 1-D compressible flow equations in the upstream direction from $x_{C}$ to the combustor entrance. When chemical reactions are present, Shapiro's method must be modified. As described in [11], we select a value of $M_{3}$ and then solve the one-dimensional conservation equations until the flow thermally chokes. A shooting method is then used to find the correct value of $M_{3}$ so that the thermal choking condition [Eq. (18)] is satisfied at the point where the local Mach number reaches unity.

\section{F. Method to Compute Unstart}

This work considers quasi-steady changes that occur, for example, by slowly increasing the fuel flow rate, which slowly raises the isolator backpressure $p_{3}$. Faster changes, such as a rapid change in angle of attack, cannot be analyzed using this quasi-steady-state assumption. Incipient unstart is the very first condition at which either the length of the isolator shock train equals the length of the isolator or the pressure ratio $p_{3} / p_{2}$ across the isolator equals the normal shock limit. Measurements of an isolator shock train $L_{\mathrm{ST}}$ by Fotia and Driscoll [28, $\underline{30]}$ and Ikui et al. [31] have been correlated by the following relation:

$$
\frac{L_{\mathrm{ST}}}{H}=\frac{1}{0.228} \ln \left(\frac{M_{2}^{2}}{M_{3}^{2}} \frac{1+((\gamma-1) / 2) M_{3}^{2}}{1+((\gamma-1) / 2) M_{2}^{2}}\right)
$$

where $H$ is the isolator height. When the fuel flow rate is increased, the isolator backpressure $p_{3}$ will increase, and the isolator exit Mach number $M_{3}$ will decrease. The previous equation indicates that this will increase the length of the shock train.

The length of the shock train is then used to determine the lengthbased unstart margin using the equation

$$
\beta=\frac{L_{\mathrm{ISO}}-L_{\mathrm{ST}}}{L_{\mathrm{ISO}}}
$$

Unstart due to the shock train extending upstream of the inlet occurs when $\beta \leq 0$. Quasi-steady incipient unstart occurs when $\beta=0$. Unstart also can occur if the isolator backpressure exceeds that of a normal shock, and this occurs when $\varepsilon=0$, where

$$
\varepsilon=\frac{p_{3}}{p_{2}}-\frac{2 \gamma}{\gamma+1} M_{2}^{2}+\frac{\gamma-1}{\gamma+1}
$$

Incipient unstart is defined to occur if either $\beta$ or $\varepsilon$ has decreased to zero. 


\section{G. Calculation of Ram-Scram Transition}

The following method is employed to compute the flight Mach number $M_{\infty}$ at which ram-scram transition begins. It is first assumed that the MAX-1 vehicle flies along a constant-dynamic-pressure ascent trajectory similar to that sketched in Fig. 2. First, a high Mach number is selected, and the vehicle is trimmed to compute the equivalence ratio needed to provide the required thrust. The trim method is described in Appendix B. For the initial large value of $M_{\infty}$, the flow will remain supersonic. Then, the value of $M_{\infty}$ is reduced, and the vehicle is retrimmed to compute a new ER value, and this process is repeated until the Mach number decreases to unity somewhere in the combustor. This value of $M_{\infty}$ is defined to be the transition Mach number. It is the smallest value of $M_{\infty}$ for which a fully supersonic solution exists. At values of $M_{\infty}$ below the transition Mach number, only a ram-mode solution is possible. As a result, there is no simulation of the full trajectory; only individual points along the trajectory are analyzed.

The method is assessed by comparing calculations to an experiment $[28,30]$, and the results are shown in Fig. 6. The black curve is the ram-scram transition boundary computed by MASIV for the same geometry as $[28,30]$. The lower gray region represents the experimental measurement. Some differences are expected because the experimental flow is not truly 1-D as it is modeled within MASIV.

\section{Vehicle Results}

This section discusses the unstart margin and ram-scram transition for the MAX-1 vehicle shown in Fig. 1 . The fuel is hydrogen, and the combustor divergence angle is $3.11 \mathrm{deg}$. In all cases, the vehicle is trimmed as it follows a trajectory along which two quantities are held constant: the dynamic pressure $q_{\infty}$ and the vehicle acceleration along the velocity vector $(\dot{V})$. The vehicle was trimmed using the MASTrim code that is described in Appendix B. The role of several important parameters was investigated: Mach number, dynamic pressure, acceleration, and inlet geometry.

\section{A. Quasi-Steady Incipient Unstart Margin}

Figure 7 shows an operating map of the unstart margin for steady, level flight. The dynamic pressure is varied between 50 and $100 \mathrm{kPa}$, and lines of constant dynamic pressure are shown. Figure 7 shows that, if the dual-mode engine is ignited at point $\mathrm{A}(h=2 \overline{0} .7 \mathrm{~km}$, $\left.M_{\infty}=4.55\right)$, the engine is in the ram mode, and the unstart margin based on length is 0.05 . From point A, the engine will unstart if $M_{\infty}$ is decreased to less than 4.5 or if the altitude is increased to more than $22 \mathrm{~km}$. However, if the Mach number is increased (slowly, so that the quasi-steady assumption remains valid) such that the conditions move to the right along the $q_{\infty}=70 \mathrm{kPa}$ contour toward point $\mathrm{C}$, the

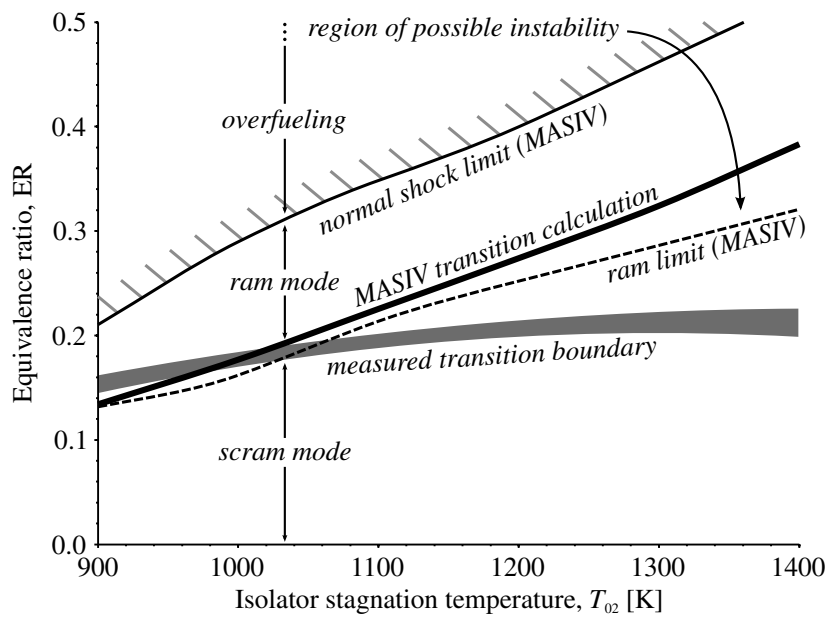

a) Measured and calculated ram-scram transition

Fig. 6 Assessment of the predicted ram-scram transition. Gray region is measured limit of $[\underline{28}, \underline{30}]$. The instability region is discussed in Sec. IV.D.

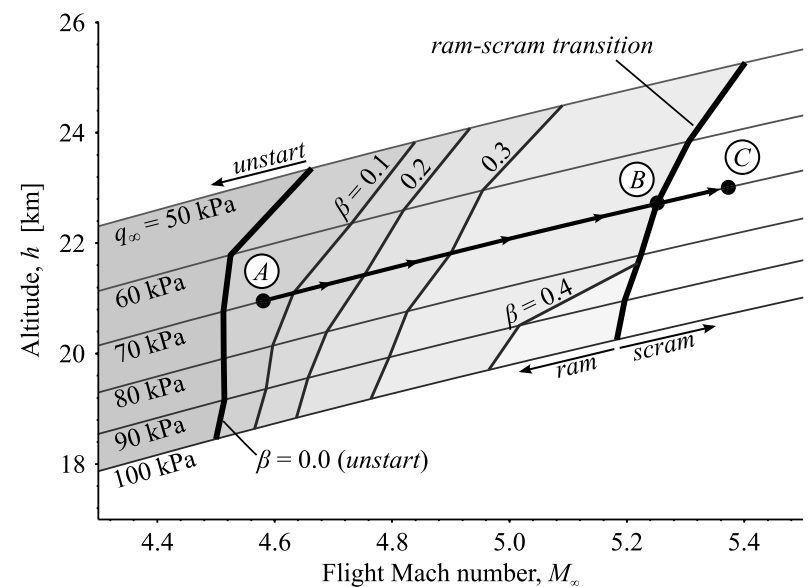

Fig. 7 Contours of unstart margin and ram-scram transition for trimmed steady level flight for dynamic pressures between 50 and $100 \mathrm{kPa}$. Unstart occurs when the unstart margin $\beta$ equals zero.

unstart margin $\beta$ increases. At point $\mathrm{B}$, ram-to-scram transition is predicted to occur, and once the unsteady transition process is complete, the engine operates in the scram mode, where only a weak shock train normally exists.

Figure 8 shows the effect of Mach number and acceleration $\dot{V}$ on the unstart margin, assuming a constant dynamic pressure of $q_{\infty}=100 \mathrm{kPa}$. Several constant-acceleration trajectories are shown, and some new prevalent trends are visible. Consider the trajectory with a net acceleration of $\dot{V}=1 \mathrm{~m} / \mathrm{s}^{2}$. The flight-path angle is determined by the assumption of constant dynamic pressure and remains below 3 deg. Trajectories with constant dynamic pressure serve as a baseline point of comparison for further investigation. Evidence suggests that scram-only optimal trajectories have nearly constant dynamic pressure, but fuel consumption can be reduced significantly from this baseline for ram-mode and transitional trajectories [32]. The minimum Mach number at which the engine can be ignited with an unstart margin $\beta \geq 0.05$ is labeled point $\mathrm{A}$ $\left(M_{\infty}=5.05\right)$ in Fig. 8. If the $\dot{V}=1 \mathrm{~m} / \mathrm{s}^{2}$ trajectory is followed, ram-scram transition occurs at point B $\left(M_{\infty}=5.45\right)$. The solution then moves to point $\mathrm{C}$, which is a scram-mode solution with a weak isolator shock train $(\beta=1.0)$.

Ram-mode solutions that are farther from transition have longer shock trains and hence lower unstart margin. Therefore, understanding unstart margin is an extension of understanding the trends

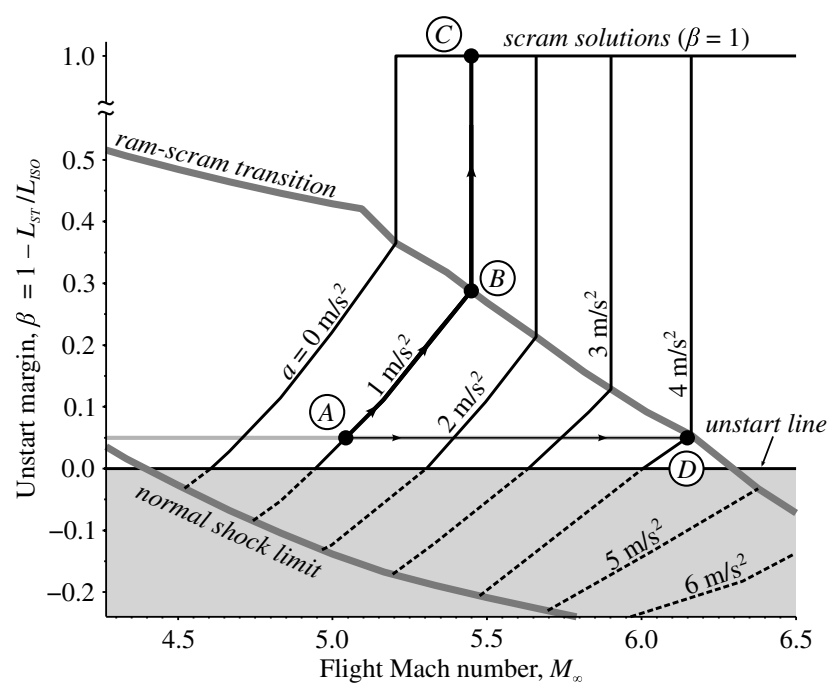

Fig. 8 Unstart margin for constant-acceleration, constant-dynamicpressure $\left(q_{\infty}=100 \mathrm{kPa}\right)$ trajectories. When $\beta<0$ (gray area), the isolator is unstarted. 
that are important for ram-to-scram transition. Increasing the flight Mach number increases $M_{3}$ and $T_{03}$, and this promotes transition from ram mode to scram mode. Although the equivalence ratio increases with $M_{\infty}$ to keep the ratio of heat release to captured enthalpy approximately constant, the trend as $M_{\infty}$ increases is to transition from ram mode to scram mode. In fact, for sufficiently high flight Mach numbers, it is not possible to burn enough fuel to choke the flow.

The effect of acceleration is also shown in Fig. $\underline{8}$. Increasing the acceleration at a fixed Mach number forces the operating condition to move downward along a vertical line in Fig. $\underline{8}$ and thus toward unstart. This is because larger acceleration requires more thrust, and thus the equivalence ratio increases. This raises the backpressure on the isolator $\left(p_{3}\right)$ as well as the length of the shock train.

It is also seen that the trajectory of maximum acceleration is a horizontal line that is close to the unstart limit. The gray line in Fig. 8 is the maximum-acceleration trajectory assuming a value of $\beta_{\text {min }}=0.05$. At $M_{\infty}=5.05$ (point A), this acceleration is $\dot{V}=$ $1 \mathrm{~m} / \mathrm{s}^{2}$; when $M_{\infty}=5.7$, the acceleration can be increased to $3 \mathrm{~m} / \mathrm{s}^{2}$; and at $M_{\infty}=6.15$ (point D), the maximum acceleration is $4 \mathrm{~m} / \mathrm{s}^{2}$. One consideration that is not directly discussed here is that fuel is also used for active cooling of the vehicle. In some cases, the cooling requires equivalence ratios greater than unity. The maximum-acceleration trajectory in Fig. $\underline{8}$ limits how much fuel can be injected.

Figure 9 shows the lines where unstart margin is zero on the flight corridor map for varying acceleration. The unstart limits have a positive slope for the following reason. Consider points A and B in Fig. 9 , and assume an acceleration of $\dot{V}=2 \mathrm{~m} / \mathrm{s}^{2}$ at both points. The Mach number is the same $\left(M_{\infty}=5.7\right)$, but point $\mathrm{B}$ is at a higher altitude. The weight of the vehicle is the same at both points, and so the lower dynamic pressure at point B means that a larger lift coefficient is needed. The result is a larger drag coefficient at point $B$ and thus a higher equivalence ratio (ER). A larger equivalence ratio increases the backpressure on the isolator and creates a longer shock train, which causes unstart at point $\mathrm{B}$, whereas point $\mathrm{A}$ is far from unstart.

The effect of increased net acceleration $\dot{V}$ is to decrease the slope of the unstart limits (thick black curves in Fig. 9). Both thrust and drag are approximately proportional to dynamic pressure when the Mach number, angle of attack, and equivalence ratio are held constant. Then, the net acceleration can be approximated:

$$
m \dot{V} \approx q_{\infty} S\left(C_{T}-C_{D}\right)
$$

where $C_{T}$ is the thrust coefficient, and $S$ is a reference area. A fixed positive value of $C_{T}-C_{D}$ results in a lower acceleration for a lower

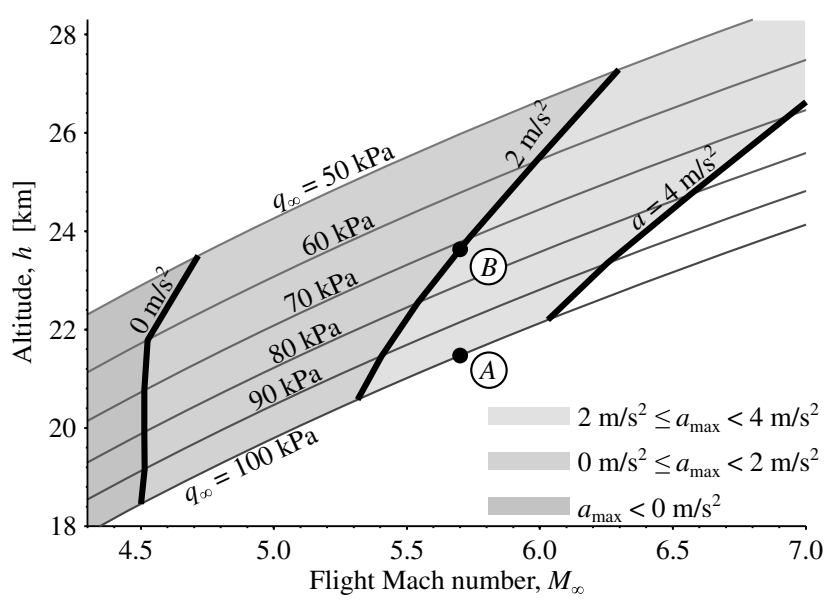

Fig. 9 Unstart boundaries (thick black lines) plotted on the flight corridor map for varying vehicle acceleration $\dot{V}$. Unstarted flight conditions are to the left of the thick black lines. value of $q_{\infty}$, and as a result, the unstart margin and other aspects of the performance are highly sensitive to altitude when $\dot{V}>0$.

\section{B. Ram-Scram Transition}

In this section, ram-scram transition boundaries are shown for several variations on the vehicle design. For all trajectories, the acceleration $\dot{V}$ and dynamic pressure $q_{\infty}$ are held constant. Dynamic pressures from 50 to $100 \mathrm{kPa}$ are used. Section IV.B.1 shows the location of ram-scram transition for the MAX-1 vehicle as presented in Fig. 1 but with varying values of acceleration. Section IV.B.2 considers slight modifications to the inlet geometry.

\section{Acceleration}

Figure 10 shows the flight condition at which the MAX-1 vehicle transitions from ram mode to scram mode as a function of acceleration and dynamic pressure. The gray lines show trajectories with constant dynamic pressure. A higher acceleration increases the transition Mach number because the thrust required is larger. With the resulting increased equivalence ratios and corresponding heat release, the engine remains in ram mode longer. This analysis matches the unstart discussion from Sec. IV.A.

One thing to note is that the transition curve in Fig. 10 marked $4 \mathrm{~m} / \mathrm{s}^{2}$ lies only slightly to the right of the unstart limit curve in Fig. 9 that is marked $4 \mathrm{~m} / \mathrm{s}^{2}$. Thus, at high acceleration of $4 \mathrm{~m} / \mathrm{s}^{2}$, there is only a small region of ram-mode operation. For smaller accelerations, the curves in Figs. 9 and 10 lie farther apart, and so there is a much larger region of ram-mode operation. Higher accelerations cause the vehicle to remain in ram mode at higher Mach numbers, which results in longer shock trains according to Eq. (19). If $M_{2}$ is high enough, then even an isolator with $M_{3}=1$ will be unstarted, with the result that no ram-mode solution is possible.

\section{Inlet Design}

This section describes the effects of a changing inlet design on the ram-scram transition. This differs from the previous subsection in that it involves slight changes to the vehicle shown in Fig. 1 . Throughout this subsection and the next, the acceleration is always $\dot{V}=0 \mathrm{~m} / \mathrm{s}^{2}$, corresponding to steady, level flight.

Four different inlet designs optimized for single conditions are considered, and they are named geometries M6, M7, M8, and M9. In each case, the inlet consists of three panels, and the total inlet length is $12 \mathrm{~m}$. Each design has a different set of panel inclination angles and panel lengths that are given in Table 1. Panels 1, 2, and 3 connect the leading edge of the vehicle to the isolator, and $L_{4}$ describes the length of the internal cowl panel that connects the cowl leading edge to the isolator. Panels 3 and 4 both have the angle $\theta_{3}$.

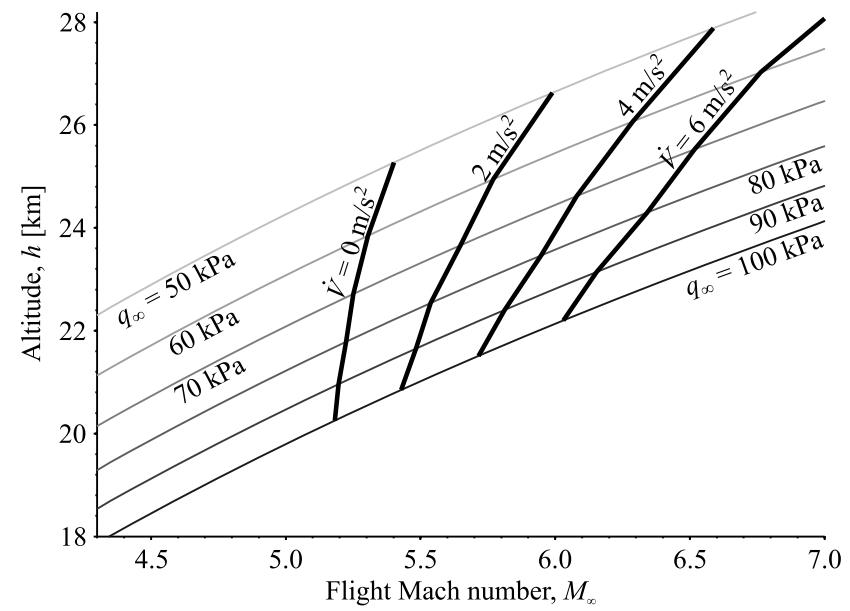

Fig. 10 Ram-scram transition boundaries assuming constant acceleration and constant dynamic pressure. For a selected acceleration, ram mode is to the left of the black line. 
Table 1 Ramp angles $\theta$, lengths $L$, and area ratio $A_{1} / A_{2}$ for four inlet geometries (M6-M9)

\begin{tabular}{lrrrr}
\hline \hline Parameter & \multicolumn{1}{c}{ M6 } & \multicolumn{1}{c}{ M7 } & \multicolumn{1}{c}{ M8 } & \multicolumn{1}{c}{ M9 } \\
\hline$\theta_{1}$, deg & 9.28 & 7.81 & 6.73 & 5.90 \\
$\theta_{2}$, deg & 22.62 & 19.12 & 16.59 & 14.67 \\
$\theta_{3}$, deg & 12.30 & 10.34 & 8.94 & 7.89 \\
$L_{1}, \mathrm{~m}$ & 8.58 & 8.40 & 8.30 & 8.24 \\
$L_{2}, \mathrm{~m}$ & 5.62 & 5.62 & 5.60 & 5.57 \\
$L_{3}, \mathrm{~m}$ & 0.07 & 0.07 & 0.08 & 0.08 \\
$L_{4}, \mathrm{~m}$ & 0.97 & 0.95 & 0.93 & 0.92 \\
$A_{1} / A_{2}$ & 13.84 & 15.17 & 16.01 & 16.58 \\
\hline \hline
\end{tabular}

The M6 geometry is an inlet that is designed for three goals; it provides the minimum pressure loss at its design flight Mach number of 6 such that strong shock interactions do not occur for flight Mach numbers between 4 and 8 , and it provides a static pressure ratio of $r_{p}=p_{2} / p_{\infty}=70$ at Mach 6 . The constraint on strong shock interactions is imposed to ensure smooth performance curves because interactions have previously been shown to cause large changes in performance [9]. An optimization code based on the work by Smart [33] is used to determine the values of angles $\left(\theta_{1}, \ldots, \theta_{3}\right)$ and lengths $\left(L_{1}, \ldots, L_{4}\right)$ for each of the panels that meets these constraints. The inlet optimization is performed at a single point, and the constraints are applied with the intent to make the performance more robust. Optimization of the inlet to design to minimize fuel consumption over a full trajectory has not been performed. The remaining designs, M7, M8, and M9, meet similar constraints but are based on design Mach numbers of 7, 8, and 9, respectively.

Figure 11 indicates how the inlet shock patterns differ between geometries M8 and M9. In both cases, $M_{\infty}=5.8, q_{\infty}=100 \mathrm{kPa}$, and $\dot{V}=2 \mathrm{~m} / \mathrm{s}^{2}$. Notice that there are more shock interactions in Fig. $11 \mathrm{~b}$ than in Fig. 11a. In fact, the inlet geometry of Fig. 11 a causes the combustion to occur in scram mode, whereas it occurs in ram mode for Fig. 11b. Small changes in the inlet panel angles were found to have a major effect on both shock location and ram-scram transition.

Figure 12 shows that the ram-scram transition Mach number increases as the inlet geometry is changed from M6 up to M9. That is, an inlet designed for a higher flight Mach number will undergo ramscram transition at a higher Mach number than another inlet designed for a lower speed. The reason for this is that the M9 design is operating far outside its intended operating range at a flight Mach number around 5. As a result, there are more shock interactions in the

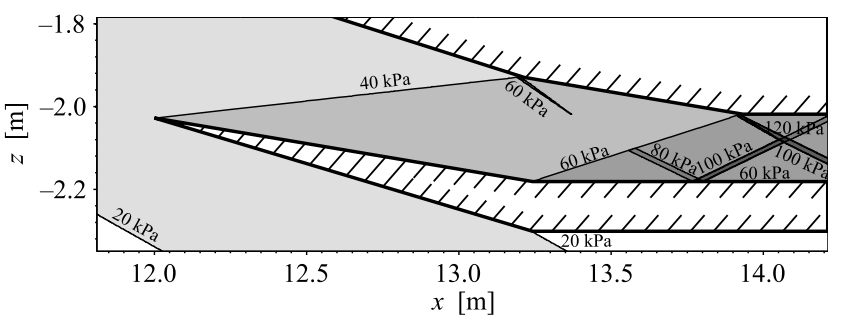

a) Inlet cowl region for M8 design

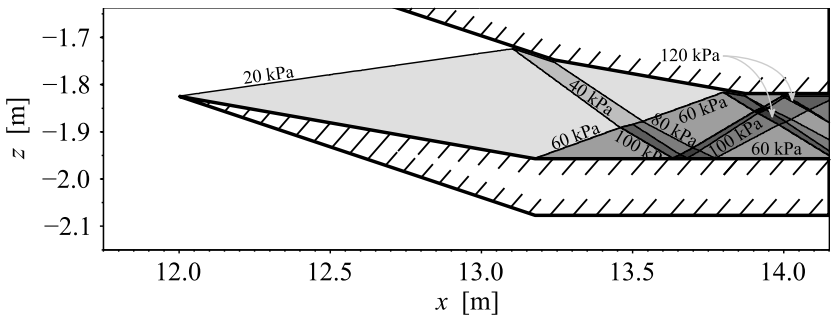

b) Inlet cowl region for M9 design

Fig. 11 Pressure contours for two vehicles at a trimmed flight condition with $q_{\infty}=100 \mathrm{kPa}, M_{\infty}=5.8$, and $\dot{V}=2 \mathrm{~m} / \mathrm{s}^{2}$. The M8 vehicle is in scram mode, whereas the $M 9$ is in ram mode. inlet, the overall performance is lower, and more fuel needs to be burned to maintain adequate thrust. The increased fueling tends to keep the combustor in ram mode longer than it would for an inlet designed for lower speeds.

\section{Differences on Either Side of the Ram-Scram Boundary}

One aspect of the ram-scram transition is that large changes in the wall pressure can occur. These changes have been measured in the lab-scale experiments of $[28,30]$. The reason for the change in wall pressure is that the engine has a downstream thermally choked boundary condition while it operates in the ram mode, but this boundary condition is not present in scram mode. The Mach number profiles undergo the significant change that is plotted in Fig. 13.

The change in wall pressure could lead to corresponding changes in thrust, lift, and drag forces, and this could lead to loss of vehicle control. For this reason, improved predictions of the wall pressure on both sides of transition can be of value to the design of a control system.

Figure 13 shows the static pressure and Mach-number profiles before and after a ram-scram transition. To generate the conditions in Fig. 13, a ram-mode solution near the boundary of ram-scram transition is found. The acceleration selected is $\dot{V}=2 \mathrm{~m} / \mathrm{s}^{2}$, and the selected dynamic pressure is $q_{\infty}=100 \mathrm{kPa}$. From Fig. 10, this leads to the flight Mach number of $M_{\infty}=5.45$. Then, after finding the trimmed equivalence ratio for those flight conditions, the equivalence ratio was lowered by 0.01 to cause transition to scram mode. As shown in Fig. 13, this causes a large change in both the pressure and Mach number profiles in the isolator and combustor.

Although this shift in internal flow conditions is worthy of study, we are mostly interested in the changes in forces and moments. The computations indicate that there is a corresponding $25 \%$ drop in thrust from 192 to $144 \mathrm{kN}$ ). As a result, the vehicle acceleration drops by about $1.5 \mathrm{~m} / \mathrm{s}^{2}$ when the engine goes into scram mode. The primary cause is that the combustion is more complete in ram mode because the air velocity is smaller, and there is more time for the fuel to burn than in scram mode. Despite the large change in thrust, the net pitching moment changes by only $2 \%$.

\section{Region of Potential Instabilities}

It was found that there is a small region in which both ram and scram solutions are mathematically possible. This region is shown in Fig. 6 between the solid black curve and the dashed curve. In the ram mode, the combustor is thermally choked, and relatively strong shocks occur in the isolator. In the corresponding scram mode, the isolator shocks are weak, and thermal choking does not occur.

When two solutions are mathematically possible, the system may become unstable and jump to the other solution. More experimental research is needed to determine if the engine becomes unstable as ram-scram transition is approached.

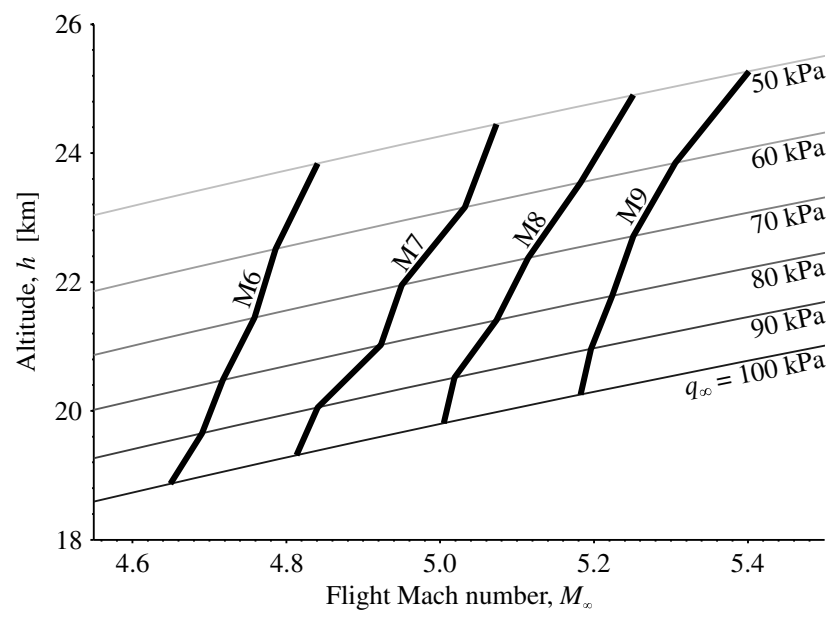

Fig. 12 Ram-scram transition boundaries (thick black curves) for varying inlet geometries. 


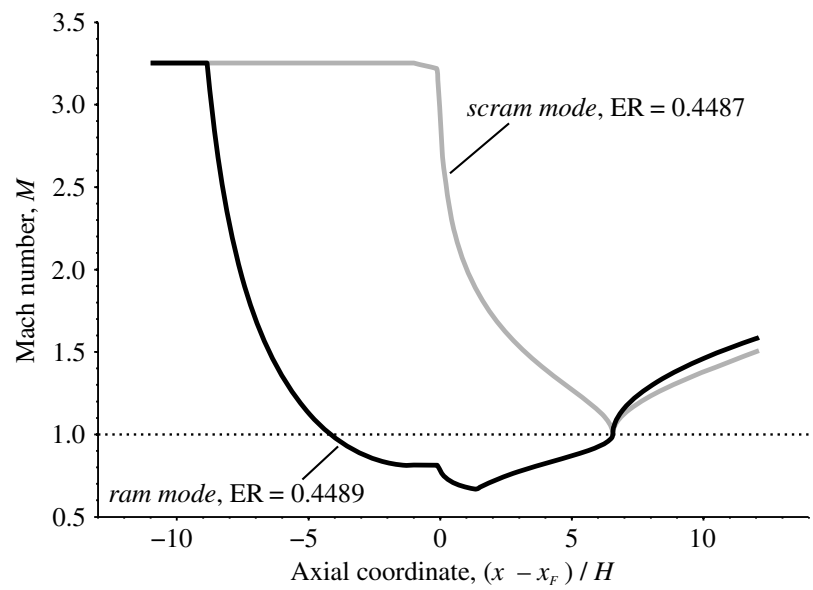

a) Mach number profile

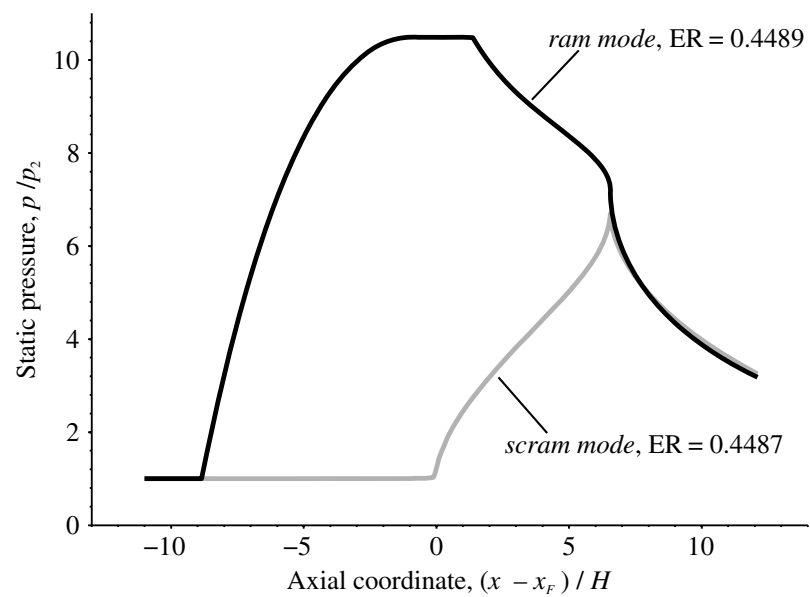

b) Static pressure profile

Fig. 13 MASIV computations of changes in local states around ramscram transition. The acceleration for the ram case is $2.00 \mathrm{~m} / \mathrm{s}^{2}$ and $0.53 \mathrm{~m} / \mathrm{s}^{2}$ for the scram case.

The existence of two solutions near the ram-scram boundary may indicate that ram-scram transition occurs at a condition different from scram-ram transition. If this is the case, there will be conditions for which an engine can operate in either ram mode or scram mode depending on whether the equivalence ratio was increased or decreased to get to that condition. Other authors have recently modeled hysteresis relating to ram mode and scram mode in a similar engine [34]. Experimental research has not identified any hysteresis phenomenon, but more evidence is needed.

\section{Conclusions}

Ram-scram transition and engine unstart limits are computed along ascent trajectories and plotted on the flight corridor map. A dual-mode combustor will undergo quasi-steady incipient unstart (the shock train just begins to exceed the isolator length) if the vehicle flies too high, too slow, or at too great of an acceleration. Actions that will cause a vehicle to transition from ram mode to scram mode include increasing the Mach number, decreasing the altitude, and decreasing the acceleration. These boundaries are calculated using a reduced-order model, and the length of the shock train is computed throughout the ram-mode flight envelope. Unstart and ram-scram transition are well-known phenomena but previously have not been calculated in terms of flight condition variables for a trimmed vehicle.

Four different inlet geometries are considered, each with different wall panel angles and lengths. Each of the four inlet designs has significant differences in the Mach number at which ram-scram transition occurs. Maximum acceleration in the ram mode, which is limited by unstart, is larger at higher flight Mach numbers. Finally, for the largest accelerations, the unstart limit is close to the ram-scram transition boundary.

The ram-scram transition prediction was compared to experimental results, and the average difference between the model and the experimental data is a $13 \%$ difference in the equivalence ratio. A discontinuity in the thrust at ram-scram transition is predicted by the model due to the difference in combustion efficiency between ram mode and scram mode. A region of possible instability or hysteresis in the engine is identified near ram-scram transition. These results highlight the need for more experimental data describing ram-scram transition including force measurements.

\section{Appendix A: Isolator Pressure Rise and Separated Boundary-Layer Model}

The constant-area isolator model from Heiser and Pratt [27] is used to calculate the isolator pressure rise and separated boundary-layer area for a given inlet Mach number $M_{2}$ and outlet Mach number $M_{3}$. Heiser and Pratt considered a pipe with no wall friction; the momentum equation can be applied to prove that the impulse function $p A+\dot{m} u$ is a conserved quantity in the axial direction. At the downstream end of the isolator (station 3), the central core has an area $A_{3 c}$, whereas the geometric area $A_{3}$ is equal to the area at the upstream end of the isolator, $A_{2}$. It is assumed that all of the mass flow passes through the core, and none passes through the separated flow area outside the core. Therefore, the conservation of momentum in the $x$ direction becomes

$$
p_{2} A_{2}+\rho_{2} u_{2}^{2} A_{2}=p_{3} A_{2}+\rho_{3} u_{3}^{2} A_{3 c}
$$

whereas conservation of mass states that

$$
\rho_{2} u_{2} A_{2}=\rho_{3} u_{3} A_{3 c}
$$

Assuming an ideal gas and no heat transfer to the walls, the solution of these conservation equations yields two new equations:

$$
\begin{gathered}
\frac{p_{3}}{p_{2}}=1+\gamma M_{2}^{2}-\gamma M_{2} M_{3} \sqrt{\frac{1+((\gamma-1) / 2) M_{2}^{2}}{1+((\gamma-1) / 2) M_{3}^{2}}} \\
r_{3 A}=\frac{A_{3 c}}{A_{2}}=\frac{1}{\gamma M_{3}^{2}}\left(\left(1+\gamma M_{2}^{2}\right) \frac{p_{2}}{p_{3}}-1\right)
\end{gathered}
$$

Both $p_{2}$ and $M_{2}$ at the isolator entrance are known from the inlet calculations. For a given Mach number $M_{3}$ at the exit of the isolator, Eqs. (A3) and (A4) are used to calculate the isolator exit pressure and the size of the separated boundary layer at that point.

\section{Appendix B: External Aerodynamics and Trim}

To calculate the forces on the surfaces of the vehicle that are not part of the engine, a shock-expansion method with a viscous correction is used [B1]. The outer mold line of the vehicle is broken into triangular panels, as shown in Fig. 1a, and the angle of each panel with the freestream is used to calculate either an oblique shock wave or expansion fan. A boundary-layer correction is made using the Van Driest II method [B2].

In this work, flight is considered to be eastward at the equator so that the equations of motion are simplified. To trim the vehicle, there are three degrees of freedom: acceleration $\dot{V}$, derivative of pitch rate $\dot{Q}$, and rate of change of dynamic pressure $\dot{q}_{\infty}$. The three decision variables used to meet the trim conditions for the three degrees of freedom are angle of attack $\alpha$, equivalence ratio (ER), and elevator deflection angle $\delta_{e}$. Because there are only decision variables (for a fixed vehicle design), assuming a constant dynamic pressure $\dot{q}_{\infty}=0$ and no net change in pitch rate $\dot{Q}=0$ with a target acceleration leads to a unique value of $\alpha, \mathrm{ER}$, and $\delta_{e}$. 
[B1] Dalle, D. J., Torrez, S. M., and Driscoll, J. F., "Sensitivity of Flight Dynamics of Hypersonic Vehicles to Design Parameters," 18th AIAA International Space Planes and Hypersonic Systems and Technologies Conference, AIAA Paper 2012-5909, Sept. 2012.

[B2] Van Driest, E. R., "The Problem of Aerodynamic Heating," Aeronautical Engineering Review, Vol. 15, No. 10, 1956, pp. 26-41.

\section{Acknowledgments}

This research is funded by the U.S. Air Force Research Laboratory (AFRL)/Air Vehicles Directorate grant FA 8650-07-2-3744 for the Michigan/AFRL Collaborative Center in Control Sciences with Michael Bolender as technical monitor.

\section{References}

[1] Bolender, M. A., and Doman, D. B., "Nonlinear Longitudinal Dynamical Model of an Air-Breathing Hypersonic Vehicle," Journal of Spacecraft and Rockets, Vol. 44, No. 2, 2007, pp. 374-387. doi: $10.2514 / 1.23370$

[2] Parker, J. T., Serrani, A., Yurkovich, S., Bolender, M. A., and Doman, D. B., "Control-Oriented Modeling of an Air-Breathing Hypersonic Vehicle," Journal of Guidance, Control, and Dynamics, Vol. 30, No. 3, 2007, pp. 856-869. doi: $10.2514 / 1.27830$

[3] Skujins, T., Cesnik, C. E. S., Oppenheimer, M. W., and Doman, D. B., "Canard-Elevon Interactions on a Hypersonic Vehicle," Journal of Spacecraft and Rockets, Vol. 47, No. 1, 2010, pp. 90-100. doi:10.2514/1.44743

[4] Oppenheimer, M. W., Skujins, T., Bolender, M. A., and Doman, D. B., "A Flexible Hypersonic Vehicle Model Developed with Piston Theory," 2007 Atmospheric Flight Mechanics Conference and Exhibit, AIAA Paper 2007-6396, Aug. 2007.

[5] O'Neill, M. K., and Lewis, M. J., "Design Tradeoffs on Scramjet Engine Integrated Hypersonic Waverider Vehicles," Journal of Aircraft, Vol. 30, No. 6, 1993, pp. 943-952. doi: $10.2514 / 3.46438$

[6] Bowcutt, K. G., "Multidisciplinary Optimization of Airbreathing Hypersonic Vehicles," Journal of Propulsion and Power, Vol. 17, No. 6, 2001, pp. 1184-1190. doi: $10.2514 / 2.5893$

[7] McQuade, P. D., Eberhardt, S., and Livne, E., "CFD-Based Aerodynamic Approximation Concept Optimization of a Two-Dimensional Scramjet Vehicle," Journal of Aircraft, Vol. 32, No. 2, 1995, pp. 262269. doi:10.2514/3.46711

[8] Mor, M., and Livne, E., "Multidisciplinary Design Optimization of Reentry Vehicles: Trajectory Optimization and Sensitivities," 47th AIAA/ASME/ASCE/AHS/ASC Structures, Structural Dynamics, and Materials Conference, AIAA Paper 2006-1718, May 2006.

[9] Dalle, D. J., Fotia, M. L., and Driscoll, J. F., "Reduced-Order Modeling of Two-Dimensional Supersonic Flows with Applications to Scramjet Inlets," Journal of Propulsion and Power, Vol. 26, No. 3, 2010, pp. 545555 . doi:10.2514/1.46521

[10] Torrez, S. M., Driscoll, J. F., Ihme, M., and Fotia, M. L., "Reduced Order Modeling of Turbulent Reacting Flows with Application to Scramjets," Journal of Propulsion and Power, Vol. 27, No. 2, March-April 2011, pp. 371-382. doi: $10.2514 / 1.50272$

[11] Torrez, S. M., Dalle, D. J., and Driscoll, J. F., "New Method for Computing Performance of Choked Reacting Flows and Ram-to-Scram Transition," Journal of Propulsion and Power, Vol. 29, No. 2, 2013, pp. 433-445. doi:10.2514/1.B34496

[12] Dalle, D. J., Torrez, S. M., and Driscoll, J. F., "Rapid Analysis of Scramjet and Linear Plug Nozzles," Journal of Propulsion and Power, Vol. 28, No. 3, 2012, pp. 545-555. doi:10.2514/1.B34391

[13] Chichka, D. F., Shankar, U. J., Cliff, E. M., and Kelley, H. J., "CruiseDash-Climb Analysis of an Airbreathing Missile," Journal of Guidance, Control, and Dynamics, Vol. 11, No. 4, 1988, pp. 293-299. doi: $10.2514 / 3.20310$

[14] Rodriguez, A. A., Dickeson, J. J., Cifdaloz, O., McCullen, R., Benavides, J., Sridharan, S., Kelkar, A., Vogel, J. M., and Soloway, D., "Modeling and Control of Scramjet-Powered Hypersonic Vehicles:
Challenges, Trends, and Tradeoffs," AIAA Guidance, Navigation and Control Conference and Exhibit, AIAA Paper 2008-6793, Aug. 2008.

[15] Starkey, R. P., and Lewis, M. J., "Critical Design Issues for Airbreathing Hypersonic Waverider Missiles," Journal of Spacecraft and Rockets, Vol. 38, No. 4, 2001, pp. 510-519. doi: $10.2514 / 2.3734$

[16] Dickeson, J. J., Rodriguez, A. A., Sridharan, S., and Korad, A., "Elevator Sizing, Placement, and Control-Relevant Tradeoffs for Hypersonic Vehicles," AIAA Guidance, Navigation, and Control Conference, AIAA Paper 2010-8339, Aug. 2010.

[17] Tarpley, C., and Lewis, M. J., "Stability Derivatives for a Hypersonic Caret-Wing Waverider," Journal of Aircraft, Vol. 32, No. 4, 1995, pp. $795-803$. doi: $10.2514 / 3.46793$

[18] O'Brien, T. F., Starkey, R. P., and Lewis, M. J., "Quasi-OneDimensional High-Speed Engine Model with Finite-Rate Chemistry," Journal of Propulsion and Power, Vol. 17, No. 6, 2001, pp. 1366-1374. doi: $10.2514 / 2.5889$

[19] Starkey, R. P., "Off-Design Performance Characterization of a Variable Geometry Scramjet," 41st AIAA/ASME/SAE/ASEE Joint Propulsion Conference \& Exhibit, AIAA Paper 2005-3711, July 2005.

[20] Chavez, F. R., and Schmidt, D. K., "Analytical Aeropropulsive/ Aeroelastic Hypersonic-Vehicle Model with Dynamic Analysis," Journal of Guidance, Control, and Dynamics, Vol. 17, No. 6, 1994, pp. 1308-1319. doi: $10.2514 / 3.21349$

[21] Tetlow, M. R., and Doolan, C., "Comparison of Hydrogen and Hydrocarbon-Fueled Scramjet Engines for Orbital Insertion,” Journal of Spacecraft and Rockets, Vol. 44, No. 2, 2007, pp. 365-373. doi:10.2514/1.24739

[22] Rodriguez, A. A., Dickeson, J. J., Sridharan, S., Korad, A., Khatri, J., Benavides, J., Soloway, D., Kelkar, A., and Vogel, J., "Control-Relevant Modeling, Analysis, and Design for Scramjet-Powered Hypersonic Vehicles," 16th AIAA/DLR/DGLR International Space Planes and Hypersonic Systems and Technologies Conference, AIAA Paper 20097287, 2009.

[23] Smith, S. H., and Mungal, M. G., "Mixing, Structure and Scaling of the Jet in Crossflow," Journal of Fluid Mechanics, Vol. 357, Feb. 1998, pp. 83-122. doi:10.1017/S0022112097007891

[24] Hasselbrink, E. F., Jr., and Mungal, M. G., "Transverse Jets and Jet Flames. Part 1. Scaling Laws for Strong Transverse Jets," Journal of Fluid Mechanics, Vol. 443, Sept. 2001, pp. 1-25. doi:10.1017/S0022112001005146

[25] Hasselbrink, E. F., Jr., and Mungal, M. G., "Transverse Jets and Jet Flames. Part 2. Velocity and OH Field Imaging," Journal of Fluid Mechanics, Vol. 443, Sept. 2001, pp. 27-68. doi:10.1017/S0022112001005158

[26] "Fluent," Software Package, Rev. 12.0.16, ANSYS, Canonsburg, PA, 2009.

[27] Heiser, W. H., and Pratt, D. T., Hypersonic Airbreathing Propulsion, AIAA, Washington, D.C., 1994, pp. 342-346.

[28] Fotia, M. L., and Driscoll, J. F., "Ram-Scram Transition and Flame/ Shock-Train Interactions in a Model Scramjet Experiment," Journal of Propulsion and Power, Vol. 29, No. 1, 2013, pp. 261-273. doi:10.2514/1.B34486

[29] Shapiro, A. H., Dynamics and Thermodynamics of Compressible Fluid Flow, Ronald Press, New York, 1953, pp. 255-260.

[30] Fotia, M. L., and Driscoll, J. F., "Isolator-Combustor Interactions in a Direct-Connect Ramjet-Scramjet Experiment," Journal of Propulsion and Power, Vol. 28, No. 1, 2012, pp. 83-95. doi:10.2514/1.B34367

[31] Ikui, T., Matsuo, K., and Nagai, M., "The Mechanism of Pseudo-Shock Waves," Bulletin of the JSME, Vol. 17, No. 108, June 1974, pp. 731-739. doi:10.1299/jsme1958.17.731

[32] Dalle, D. J., Torrez, S. M., Driscoll, J. F., Bolender, M. A., and Bowcutt, K. G., "Minimum-Fuel Ascent of a Hypersonic Vehicle Using Surrogate Optimization," Journal of Aircraft (to be published).

[33] Smart, M. K., "Optimization of Two-Dimensional Scramjet Inlets," Journal of Aircraft, Vol. 36, No. 2, 1999, pp. 430-433. doi: $10.2514 / 2.2448$

[34] Cui, T., Tang, S., Zhang, C., and Yu, D., "Hysteresis Phenomenon of Mode Transition in Ramjet Engines and Its Topological Rule," Journal of Propulsion and Power, Vol. 28, No. 6, 2012, pp. 1277-1284. doi:10.2514/1.B34419 